Revista Perspectivas Online: Humanas \& Sociais Aplicadas

Agosto de 2018, Vol.8, no 22, p.37-51

ISSN: $2236-8876$ (Online)

DOI: $10.25242 / 887682220181386$

\title{
CARACTERÍSTICAS DE UM BOM PROFESSOR NA PERCEPÇÃO DE UNIVERSITÁRIOS
}

Mari Lucia Figueiredo ${ }^{1^{*}}$

\section{RESUMO}

FIGUEIREDO, M. L. Características de um bom professor na percepção de universitários. Perspectivas Online: Humanas \& Sociais Aplicadas, v. 8, n.22, p.37-51, 2018.

Um processo de ensino e aprendizagem e uma perspectiva de melhoria contínua e de crescer com qualidade e relevância foi $o$ que nos motivou a conhecer a opinião dos estudantes sobre o perfil do bom professor. Nesse contexto, o objetivo deste estudo foi identificar a opinião dos estudantes acerca das características de um bom professor. Trata-se de um estudo quanti-qualitativo, utilizando um questionário, com uma questão aberta "o que considera ser um Bom Professor". Participaram 222 universitários, de ambos os sexos, com idade variando de 18 a 62 anos, dos cursos de Enfermagem, Biologia, Química, Psicologia, Letras, Pedagogia, Geografia e História. Do conjunto de indicadores de um "Bom professor" emergem domínios do conhecimento e aspectos didáticopedagógicos, desenvolver uma boa relação com os estudantes, metodologia diversificada, dinâmico e linguagem fácil. Conclui-se que a competência profissional é importante, porém, não exclusiva, valorizando-se também características pessoais.

Palavras-chave: Percepção, Aprendizagem, Alunos/Professores.

\section{ABSTRACT}

A teaching/learning process and with a view to continuous improvement and to grow with quality and relevance, is what motivated us to know the opinion of students on the profile of a good teacher. In this context, the aim of this study was to identify the opinions of students about the characteristics of a good teacher. This is a quantitative-qualitative study using a questionnaire with an open question "what it considers to be a good teacher." Were 222 university students of both sexes, aged
18-62 years, Nursing, Biology, Chemistry, Psychology, Literature, Education, Geography and History. The set of indicators of a "good teacher" emerges areas of knowledge and didactic and pedagogical aspects develop a good relationship with the students, diversified methodology, dynamic and easy language. It is concluded that professional competence is important, but not exclusive, with the emphasis on up personal characteristics.

Keywords: Perception, Learning, Students / Teachers.

\footnotetext{
${ }^{\mathrm{T}}$ Faculdade de Tecnologia de Catanduva - FATEC - Rua Maranhão, 898, Centro, Catanduva, SP, Brasil CEP:15800-020, Brasil.

(*) e-mail: maripsydra@yahoo.com.br

Data de recebimento:15/08/2018. Aceito para publicação: 04/10/2018
} 


\section{INTRODUÇÃO}

Estabelecer boas relações com os alunos é o primeiro passo para se obter um bom ambiente de trabalho. "Para que as aulas sejam produtivas e interessantes para o aluno, ele precisa sentir-se à vontade com o professor, e isso irá facilitar seu envolvimento nas atividades e a construção dos conhecimentos com relação aos conteúdos trabalhados" (FRESCHI \& FRESCHI, 2013, p1). O ambiente escolar é um dos locais onde as relações interpessoais se intensificam, reunindo uma diversidade de conhecimentos, valores e regras, sendo notadamente, permeado por conflitos, problemas e diferenças (MOHONEY, 2002; SALES \& SOUZA, 2012). Na teia da relação "bom" professor/formação (inicial/contínua), podemos dizer que, hoje em dia, no contexto das nossas sociedades, caracterizadas por constantes e permanentes mutações (mais quantitativas do que qualitativas), "todo professor tem necessidade de atualizar métodos, técnicas e conteúdos, bem como de efetuar uma permanente auto avaliação, pois a simples prática do ensino não garante o seu melhoramento" (CUNHA, 2010 p. 42). O ensino está condenado ao retrocesso, caso não seja acompanhado de um processo profissional, bem como se não houver uma evolução no que diz respeito à própria forma de como se ensina. A competência não é necessariamente proporcional aos anos de prática, nem o melhoramento do ensino se processa de forma automática, argumenta o autor.

Há na figura do bom professor certo misticismo e fascínio que incita a curiosidade epistemológica (MENEGAZ, BACKES, CUNHA \& FRANCISCO, 2014). "Afinal, o que ele faz? É bom em que sentido? As características que lhe fazem ser entendido como bom contribuem para com o atual momento da formação em saúde? Partindo do entendimento de que se há deficiência na formação de professores do ensino superior, há algo em sua prática que poderia ser aproveitado, incorporado no sentido de auxiliar na construção de política ou programa de formação docente? "Menegaz et al., 2014, p.1049. Discussão sobre aspectos que possam influenciar no processo de ensino e aprendizagem têm sido recorrentemente estudados (VASCONCELOS et al., 2005). Mas pouco se sabe sobre a qualidade do ensino que é praticado e do nível de aprendizagem que é obtido nas instituições de ensino superior, principalmente sob a perspectiva dos atores envolvidos. Ao se conhecerem os fatores que influenciam no desempenho dos estudantes, pode-se implementar ações que visem à melhoria do processo de ensino e aprendizagem - processo esse que envolve o aluno, o professor e a instituição (SILVA, OLIVEIRA NETO, 2007). Sendo assim, tanto os alunos como os professores e as próprias instituições devem discutir e avaliar o ensino, buscando novas alternativas para aumento de sua eficácia e eficiência.

Para Martins (2000), as mudanças sociais ocorridas nos últimos anos implicaram o surgimento de instituições com vocações distintas, destacando-se: ensino e pesquisa; extensão e formação profissional. Esse crescimento, entretanto, vem acompanhado de heterogeneidade entre as instituições de ensino. Enquanto as universidades públicas tendem a focar na pesquisa e extensão, as faculdades, centros universitários e institutos privados de ensino superior possuem um foco na formação profissional. Processo semelhante na estrutura de ensino superior ocorreu em Portugal, a partir de meados da década de 1980, apresentando-se como inerente ao desenvolvimento econômico e social (TEODORO, 2005). Duderstadt (2003) atribui à globalização algumas das mudanças substanciais no ambiente educacional: o conhecimento como commodities de prosperidade econômica, segurança nacional e Welfare State, interdependência entre nações, mudanças demográficas, busca por novas prioridades sociais (pós-guerra fria), e necessidade de pensamento e ações sustentáveis. 
Já Demo (2006/2008) destaca que essas mudanças trazem, em sua essência, o caráter mercadológico, fruto da influência norte-americana e um status quo que reforça a exclusão social e a concentração de renda nas elites brasileiras e mundiais. Com uma abordagem universalista, Morin (2006) elenca sete saberes necessários à educação do futuro: a) conhecimento - é importante destacar que o ensino fornece conhecimento e saberes; b) conhecimento contextualizado - é preciso ter uma visão que possa situar o conjunto (não é a quantidade de informações que gera conhecimento pertinente, é necessária a capacidade de colocá-lo em um contexto); c) identidade humana - a missão da raça humana é civilizar o pequeno planeta em que vive; d) compreensão humana - deve-se ensinar sobre compreender uns aos outros e compreender a si mesmo, se auto examinar-se, analisar a si próprio; e) incerteza - é necessário tomar consciência de que as futuras decisões devem ser tomadas contando com o risco do erro e estabelecer estratégias que possam ser corrigidas no processo da ação; f) condição planetária - os problemas estão todos amarrados uns aos outros, é preciso mostrar que a humanidade vive em uma comunidade de destino comum; g) antropoética - os problemas da moral e da ética diferem entre culturas e na natureza humana. $\mathrm{Na}$ perspectiva do autor citado, não é necessário eliminar disciplinas, mas sim integrá-las, reunilas umas às outras em uma ciência (MORIN, 2006 p. 24).

Porém, as práticas educacionais tradicionais eram "domesticadoras" e seguiam um padrão comportamental pelo qual o professor era detentor da transmissão do saber e não devia ser questionado, mas apenas ouvido e o aluno assumia a condição de receptor passivo do conhecimento, segundo Freire (2005). O autor aponta que a educação deve partir do diálogo, isto é, de uma interação entre aluno e professor, assim, o conhecimento previamente adquirido pelo aluno, em sua prática de vida, assume importância tão grande quanto aquele trazido pelo professor. A educação se torna uma troca, uma construção conjunta de saberes. Porém, Demo (2008, p. 18) destaca que "aprender não advém necessariamente de ensinar". O aprendizado humano se dá pela forma como a mente do indivíduo percebe os símbolos experimentados, codifica-os e atribui significados aos mesmos. Nesse sentido, um ambiente adequado à aprendizagem requer: participação do aluno, técnicas e processos didáticos reconstrutivistas e interpretativos que estimulem o aluno. Nesse contexto, Alonso (2005, p. 28) ressalta que "a qualidade do processo de aprendizagem tem na convivência seu elemento catalisador". Argumenta a autora que a convivência é essencial para a relação professor-aluno-colegas. $\mathrm{O}$ contato direto com outros alunos, professores e tutores, seja por meios tradicionais ou modernos (tecnologias aplicadas na modalidade EAD), cria situações de convivência que permitem a troca de experiências e informações, possibilitando reelaborações do conhecimento produzido e em produção.

Além disso, a relação entre professor e aluno depende fundamentalmente, como afirma Silva (2005), do clima estabelecido pelo professor, da relação empática com seus alunos, de sua capacidade de ouvir, refletir e discutir o nível de compreensão dos alunos e da criação das pontes entre o seu conhecimento e o deles. $\mathrm{O}$ autor indica, também, que o professor, educador da era industrial com raras exceções, deve buscar educar para as mudanças, para a autonomia, para a liberdade possível, numa abordagem global, trabalhando o lado positivo dos alunos e para a formação de um cidadão consciente de seus deveres e de suas responsabilidades. O que tem-se observado é que o panorama da relação professor/aluno mudou completamente. Veiga (2004) afirma que um dos fatores que influenciaram essa mudança foi justamente o fato de a universidade ter ganhado nos últimos anos um público mais amplo. A autora ainda afirma que a relação, hoje, não é só pedagógica, mas também, social, profissional e afetiva. Essa relação pedagógica não é mais um campo para a homogeneização. Agora há muitas diferenças sociais, portanto, os alunos são heterogêneos e, 
muitas vezes, os professores não estão preparados para analisar estes novos valores da forma como deveriam.

Em outra perspectiva, Teixeira (2004) diz que a relação professor/aluno se perpetua nos seguintes aspectos: a) a autoridade do saber dá ao professor o poder (e os plenos poderes) dentro da sala de aula (aliás, o sistema atrai aqueles que aspiram a um poder fácil, pois favorece o exercício da autoridade e cultiva, assim, o complexo de superioridade dos educadores); b) ele é o juiz, é ele que corrige e sanciona, dá nota, avalia, arbitra, elogia ou repreende; c) é a "vedete" e o modelo, é para ele que se olha, é ele que se admira (o sistema atrai também aqueles que procuram um fácil público complacente, favorece as tendências teatrais e exibicionistas, e cultiva o complexo de Narciso em muitos educadores); d) é paternalista (ou materialista), mesmo com severidade, ele age "para o bem dos alunos" e mantém com eles um relacionamento afetivo, que lhe permite influenciá-los sentimentalmente. Esta imagem paradigmática da aula está entranhada em nossos hábitos, pois a educação é fruto desse sistema, e a ela voltamos sempre quando pensamos em ensino de adultos, camuflando e desconhecendo seu caráter arcaico, por meio de uma superabundância de tecnologia moderna. Na realidade nada mudou, pois o que vemos sempre é o professor que dá aula ou faz uma exposição, e os alunos, individualizados, ali se encontram para ouvir e aprender.

No tocante aos estudos que vêm sendo realizados, especificamente sobre características do bom professor, pode-se citar a pesquisa de Krug e Krug (2008, p13), que, em suas investigações objetivaram conhecer e analisar as características pessoais do bom professor, segundo os acadêmicos da Licenciatura em Educação Física do Centro de Educação Física e Desportos (CEFD) da Universidade Federal de Santa Maria (UFSM). A metodologia se caracterizou pelo enfoque fenomenológico sob a forma de estudo de caso com abordagem qualitativa. $O$ instrumento utilizado para a coleta de informações foi uma entrevista semiestruturada. A interpretação das informações foi a análise de conteúdo. Foram trinta e oito (38) participantes, acadêmicos da Licenciatura em Educação Física (Currículo de 1990) do CEFD/UFSM. O que mais chamou a atenção nos resultados desta investigação foi o fato de que, no rol das vinte e seis (26) características pessoais do bom professor de Educação Física, ficou evidenciado o seguinte: 1) O bom professor é aquele que em sua prática pedagógica cotidiana mostra como principais características pessoais uma 'boa didática', $o$ 'domínio do conteúdo', sendo 'respeitador', 'criativo' e 'gosta do que faz'; 2) Não foram valorizadas características como 'reflexão', ‘questionamento' e 'criticidade'; 3) Não foi citada 'nenhuma qualidade física' nas características pessoais como necessárias ao bom professor de Educação Física, entretanto, foram citadas quatorze (14) qualidades intelectuais e doze (12) qualidades sociais. Para concluir, destacamos que, em nenhum momento, as características pessoais citadas nesta investigação podem ser consideradas como um modelo acabado de desempenho docente, pois ser bom professor não é um estado de ser. É um permanente vir a ser.

Gabrielli e Pelá (2004, p. 169/170) realizaram uma pesquisa sobre o professor real e o ideal na visão de graduados de enfermagem. Para tanto, basearam-se nas categorias Icognitivo, II- didático-pedagógico e III-afetivo. O estudo contou com 71 alunos do curso de enfermagem, sendo 38 alunos $(58,4 \%)$ da escola pública e 33 alunos $(41,6 \%)$ da escola privada (ambos dos $8^{\circ}$ semestre). $\mathrm{O}$ instrumento utilizado foi um questionário contendo 60 itens descritivos de características, comportamentos e atitudes que podem ser apresentados pelo professor, listados no instrumento. As autoras destacaram 37 itens pertencentes às categorias anteriormente denominadas I, II e III. Os resultados demonstraram que os aspectos afetivos da relação professor-aluno são mediadores para que, através do domínio, tanto do 
conteúdo da disciplina, como dos aspectos didático-pedagógicos pelos docentes, o processo ensino e aprendizagem se concretize com sucesso. Também é necessário contextualizar, usar a criatividade e deixar a posição de autoridade máxima para conseguir prender o interesse dos alunos hoje em dia; é preciso estar adaptado às mudanças tecnológicas e atento à vida dos estudantes.

Menegaz, Backes, Cunha \& Francisco (2014 p. 1048) elaboraram um estudo cujo objetivo central foi analisar as características do bom professor de ensino superior na área da saúde à luz do referencial do conhecimento, base para o ensino de Lee Shulman. Os autores fizeram uma revisão integrativa a partir de artigos originais, dissertações e teses publicadas entre 1996 e 2010, na base de dados LILACS e no Banco de Teses e Dissertações da CAPES. Dos 164 estudos, sete atenderam os critérios e foram analisados de acordo com o conhecimento base. Os resultados revelaram três categorias: 1). Boas características pessoais, 2). Boas características pedagógicas e, 3). Boas características relacionais. Concluíram que bons professores têm boa abordagem pedagógica, boa relação interpessoal, estimulam a autonomia dos estudantes e demonstram qualidades pessoais como pontualidade e organização. Houve similaridade entre a descrição das características dos professores de diversas profissões da área da saúde e estas expressam a pertinência do referencial teórico de Lee Shulman para a formação docente.

Outro estudo, realizado por Marques, Oliveira, Nascimento \& Cunha (2012 p. 8), buscou identificar a opinião dos alunos de três cursos superiores de Ciências Contábeis, em Belo Horizonte, sobre as competências de seus professores que são mais valorizadas. Estas competências influenciam na definição de "bom" professor, que é uma definição histórica e contextualmente construída. Para tal, realizou-se uma amostragem por acessibilidade e aplicaram-se questionários junto a estudantes do segundo, quinto e sétimo período do curso de Ciências Contábeis, oferecido por três faculdades do Município de Belo Horizonte/MG. Para a análise, utilizou-se a abordagem quantitativa através de estatística descritiva e testes de homogeneidade e associação - especificamente, qui-quadrado $\left(\chi^{2}\right)$. Os resultados evidenciaram que nível de conhecimento, didática e segurança foram os atributos mais valorizados na definição de competência do professor, sendo avaliados como extremamente importantes para uma parcela significativa dos respondentes.

Gisi, Ens \& Eyng (2010) também investigaram alunos do curso de Pedagogia sobre o que entendem por ser "um bom professor". A amostra investigada foi constituída exclusivamente pelo sexo feminino, com idades que variou de 18 a 24 anos. Os depoimentos foram coletados através de entrevistas semiestruturadas e submetidos ao processo de análise de conteúdo (BARDIN, 1984). Observou-se que o bom professor é representado com muitos elementos em comum, o que faz pressupor a existência de uma representação que permeia o grupo entrevistado. Os resultados indicaram que o bom professor é aquele que possui conhecimento da disciplina e da metodologia, tem atitudes no que se refere à profissão e aos alunos e assume um comportamento social que ainda se constitui em elemento periférico.

Para Quintana (2003), é no pensamento hipotético-dedutivo que são desenvolvidas as funções cognitivas, destinadas à formulação de hipótese e projeções dedutivas, imprescindíveis na pesquisa científica. Os trabalhos acadêmicos de permanência e conclusão exigem que o ser humano seja possuidor desta qualificação. A realidade atual, segundo a autora, indica que nem sempre o aluno chega a esta condição. Por esse motivo, o professor deve exercer uma função de mediador, facilitando o processo de aquisição e apropriação do conhecimento. Essa mediação deve acontecer na utilização de pautas interativas, que 
favoreçam as trocas, as discussões, a reflexão crítica, a cooperação mútua e o intercâmbio entre pares, a ação interativa que se denomina "didático pedagógica".

\section{METODOLOGIA}

\subsection{Participantes}

Para realização deste estudo, desenvolvemos uma pesquisa bibliográfica, descritiva exploratória, de natureza qualitativa, que teve como objetivo identificar as características do bom professor na perspectiva de universitários.

Participaram deste estudo 222 estudantes universitários de ambos os sexos, com idade entre 18 e 62 anos $(M=40)$, observa-se que, uma faixa ampla de idade foi contemplada e a amplitude bastante acentuada, como mostra os dados acima. Quanto a amostra tivemos a seguinte representação: curso de psicologia $(n=44 ; 19,8 \%)$, pedagogia $(n=29 ; 13 \%)$, letras $(n=34 ; 15,3 \%)$, química $(n=23 ; 10,4 \%)$, biologia $(n=21 ; 9,5 \%)$, enfermagem $(n=16 ; 7,2 \%)$, história $(n=20 ; 9 \%)$ e geografia $(n=35 ; 15,8 \%)$. Os estudantes eram alunos da $1^{\text {a }}$ série de cada curso de uma instituição particular de um município do interior paulista. Na Tabela 1, podemos visualizar a distribuição dos cursos e números de participantes. O curso com maior número de participantes foi psicologia, geografia e letras.

Tabela 1:Distribuição dos participantes de acordo com o curso

\begin{tabular}{ccc}
\hline Cursos & F & F\% \\
\hline Psicologia & 44 & 19,8 \\
Geografia & 35 & 15,8 \\
Letras & 34 & 15,3 \\
Pedagogia & 29 & 13 \\
Química & 23 & 10,4 \\
Biologia & 21 & 9,5 \\
História & 20 & 9 \\
Enfermagem & 16 & 7,2 \\
\hline Total & 222 & $100 \%$ \\
\hline
\end{tabular}

Fonte: elaborada pela autora

\subsection{Instrumento}

Foi aplicado, de forma coletiva, em sala de aula, um questionário com apenas uma questão aberta "Quais características vocês achavam importantes para ser um bom professor? ". O aluno era identificado pelo ano de frequência e curso. A utilização de apenas uma questão aberta foi determinada pelo fato de não pretendermos a indução de respostas, mas sim, a espontaneidade, dado o caráter exploratório do estudo.

Utilizou-se, para correção do questionário, análise de conteúdo (BARDIN, 1984) e identificação de ideias-chave nos discursos, comparando significados verbais. Como estratégia, para sistematizar a análise dos testemunhos, baseamo-nos em Candau (1983), Feitoza, Cornelsen e Valente (2007) e Cunha (2008), cujos estudos propõem o entrelaçamento de três dimensões: Pessoais/Personalidade (relacionados ao seu caráter e atitudes); Relação Professor Aluno (relacionada às expressões que revelam sua conduta em relação ao seu 
comportamento com o aluno) e Didático/Pedagógico (relacionada às suas atividades laborais). Os critérios para categorização podem ser: semântico ou temático, quando agrupados todos os temas que têm o mesmo significado; léxico, que corresponde à classificação das palavras, segundo seu sentido, com emparelhamento dos sinônimos e dos sentidos próximos; sintático, que agrupa verbos e adjetivos; e expressivo, que classifica as diversas perturbações da fala.

\subsection{Procedimento}

Ao ser iniciado o estudo, na faculdade em questão, todos os alunos das primeiras séries foram contatados e a eles foi explicado o propósito do estudo, solicitando que assinassem o Termo de Consentimento Livre e Esclarecido. Em seguida, iniciou-se a aplicação dos questionários, que aconteceu coletivamente na própria sala, nos intervalos das aulas.

Ressalta-se que, durante a aplicação do questionário, procurou-se assegurar o perfeito entendimento da questão, bem como foi solicitado que os participantes respondessem com o maior nível de detalhamento possível. Tais procedimentos visaram garantir o foco dos respondentes no tema e obter o maior número possível de informações para melhor compreensão do tema pesquisado.

Os pesquisadores entregavam o questionário e, após o preenchimento deste, faziam a coleta. Esse procedimento durou em torno de 30 minutos. Os alunos respondiam individualmente.

\section{RESULTADOS E DISCUSSÃO}

Inicialmente, serão apresentados e discutidos os resultados do estudo representados pelos alunos que participaram da pesquisa e seus respectivos cursos: psicologia, letras, pedagogia, enfermagem, biologia, química, história e geografia. O primeiro passo foi estabelecer os elementos comuns, recorrentes à análise de conteúdo, estabelecendo, assim, a escolha das unidades de texto que correspondem ao conteúdo visando uma análise temática (PASQUALI, 2013). Após esse procedimento, avançamos para identificação das unidades de significados mediante a frequência, sendo que a unidade de texto aumenta com a frequência da aparição. A partir dessa etapa, foram estabelecidas as dimensões já citadas anteriormente (Pessoais e Personalidade; Relação Professor Aluno e Didático e Pedagógico). Para maior compreensão, buscamos identificar, nos discursos dos alunos, a frequência com que cada uma das dimensões é identificada em relação aos cursos representados pelos alunos.

$\mathrm{Na}$ Tabela 2, podemos visualizar, de acordo com os dados coletados, que visam caracterizar as características do bom professor, pelos graduandos, os resultados apresentados que apontam aos domínios do conhecimento e aspectos didático-pedagógicos. Essa dimensão foi apontada por seis dos oito cursos participantes: História $(63,3 \%)$; Química $(50 \%)$; Biologia (44,9\%); Letras (44,8\%); Enfermagem (44\%) e Psicologia (39,7\%). Esses dados nos remetem a outros encontrados, onde o aluno coloca que não deseja um professor "bonzinho" e sim "intelectualmente capaz e afetivamente maduro". Gabrielli \& Pelá (2004 p.171). Os graduandos demonstraram que valorizam a importância da competência profissional, o que corresponde à imagem de um profissional atualizado, eficiente e preocupado com a qualidade de ensino. Contrariando alguns estudos, os nossos resultados apontaram que os graduandos valorizam mais os aspectos da atividade profissional do professor, ou seja, àqueles demonstrados pelo professor em sala de aula, no exercício das atividades docentes, como, por 
exemplo, conhecimentos gerais e da disciplina, formação, domínio do conteúdo, atualizado, criativo e dinâmico, os quais têm maior peso para os alunos mais velhos do que para alunos dos primeiros anos de estudo.

Já os alunos do curso de Pedagogia valorizam as características relacionadas à categoria pessoal e de personalidade $(43,8 \%)$, que são aquelas relacionadas à interação positiva entre o professor e o aluno, refletindo uma preocupação com uma educação mais humanista. E os alunos do curso de Geografia acham que para ser um bom professor, o docente tem de ter características voltadas para relação a professor/aluno $(44,6 \%)$. A afetividade é uma característica que alguns professores possuem, o que os tornam mais próximos dos alunos. Certas atitudes e valores estabelecidos em bases de relacionamento afetivo vão refletir na forma com a qual o professor desenvolverá o conteúdo da matéria e sua habilidade de ensino, Cunha (2008). Além das frequências dos cursos nas categorias em relação a prática docente, também avançamos para a análise da média e desvio padrão das categorias. Tabela 2.

Tabela 2: Resultados das frequências dos cursos nas categorias em relação a pratica docente

\begin{tabular}{|c|c|c|c|c|c|c|}
\hline \multirow{3}{*}{$\begin{array}{c}\text { Cursos } \\
\text { Psicologia }\end{array}$} & \multicolumn{2}{|c|}{$\begin{array}{c}\text { Pessoais e } \\
\text { Personalidade }\end{array}$} & \multicolumn{2}{|c|}{$\begin{array}{l}\text { Relação Professor } \\
\text { Aluno }\end{array}$} & \multicolumn{2}{|c|}{$\begin{array}{l}\text { Didático } \\
\text { Pedagógico }\end{array}$} \\
\hline & $\mathrm{F}$ & $\mathrm{F} \%$ & $\mathrm{~F}$ & $\mathrm{~F} \%$ & $\mathrm{~F}$ & $\mathrm{~F} \%$ \\
\hline & 38 & $27 \%$ & 47 & $33,3 \%$ & 56 & $39,7 \%$ \\
\hline Letras & 50 & $23,8 \%$ & 66 & $31,4 \%$ & 94 & $44,8 \%$ \\
\hline Pedagogia & 60 & $43,8 \%$ & 23 & $16,8 \%$ & 54 & $39,4 \%$ \\
\hline Biologia & 21 & $21,1 \%$ & 34 & $33,2 \%$ & 45 & $44,9 \%$ \\
\hline Enfermagem & 19 & $19 \%$ & 37 & $37 \%$ & 44 & $44 \%$ \\
\hline Química & 28 & $21 \%$ & 39 & $29 \%$ & 67 & $50 \%$ \\
\hline Geografia & 41 & $26,1 \%$ & 70 & $44,6 \%$ & 46 & $29,3 \%$ \\
\hline História & 23 & $22,1 \%$ & 17 & $15,6 \%$ & 69 & $63,3 \%$ \\
\hline Média & 35 & $\overline{44,83)}$ & $41,6($ & $18,71)$ & & $P=16,95)$ \\
\hline Variância & 2 & & & & & 289,42 \\
\hline
\end{tabular}

Nota. $\mathrm{DP}=$ desvio padrão

Fonte: elaborada pela autora

Assim, este estudo pretendeu também identificar o que os alunos apontaram como as características mais frequentes no comportamento de um bom professor. As frequências das respostas e suas respectivas porcentagens podem ser visualizadas na Tabela 3.

A Tabela 3 mostra a distribuição das respostas nas três categorias que foram trabalhadas nesse estudo, nos oito cursos pesquisados. As características que aparecem como mais importantes para o bom professor foram: amizade $(11,8 \%)$, saber se expressar $(11,2 \%)$, estar atualizado (11\%), possuir domínio do conteúdo $(9,8 \%)$ e ser criativo $(9,2 \%)$.

O relacionamento (amizade) foi apontado pelos alunos como a característica mais importante de um bom professor. A amizade supõe certa semelhança, um número determinado de interesses comuns e o diálogo. Além disso, existe um elemento emocional, uma resposta intuitiva espontânea. Os amigos se comportam como irmãos, mas, além da fraternidade, eles sentem admiração, satisfação e enriquecimento mútuo pelo fato de estarem 
juntos, e ultrapassam a nossa capacidade de definir as muitas sensações envolvidas nesse tipo de relacionamento humano. Em uma pesquisa desenvolvida por Cunha (2008) ficou evidente a importância do aspecto afetivo, mostrando que a ideia de professor ideal passa pela capacidade dele se mostrar próximo do aluno do ponto de vista afetivo. Porém, nem sempre se observa essa atitude no professor universitário.

Entretanto, Cunha (2008) aponta como característica fundamental de um bom professor a linguagem. Para ele, esta é a principal ferramenta de trabalho, pois é ela que transmite seu quotidiano, demonstra a forma de ser e agir do professor por meio da linguagem, que estabelece a reciprocidade dentro da relação professor-aluno. É através da comunicação, da forma de se expressar que ambos podem compreender a realidade e a vida quotidiana de cada um.

Subjacentes aos significados de um bom professor estão um conjunto de indicadores, dos quais podemos evidenciar o domínio dos conteúdos e atualizados. Independente do curso que frequentam, os estudantes parecem concordar que é muito importante na sala de aula, o instruir bem, o que nos remete ao domínio do conhecimento da matéria e a sua atualização frente aos novos conceitos. Como foi possível verificar, a criatividade também, foi apontada como uma característica importante do bom professor. Sobre esse aspecto, Kochhann (2007) ressalta que, para quem não basta o saber teórico para ser um professor comprometido com a formação integral, é preciso bem mais que mera teoria, a criatividade passa a ser supremo do processo ensino aprendizagem.

Outras características como: metodologia diversificada $(8 \%)$, dinamismo $(8,3 \%)$ e alegria e ser extrovertido $(8,2 \%)$, todas com pontuação acima de $8 \%$, foram também consideradas muito importantes. A educação enquanto prática social, atua no sentido de promoção e desenvolvimento de formação do sujeito na sua totalidade, para que o mesmo possa atuar de forma ativa, respondendo as necessidades da sociedade atual. Nesse sentido, a ação educativa não é uma prática aleatória, isolada, mas sistemática e integrada. Portanto, exige planejamento, direcionamento e metodologias diversificadas que além de dinamizar a aula, possibilita a construção do conhecimento histórico. Quanto ao dinamismo, Kinight (2002) argumenta que este focaliza a paixão do professor pela profissão e seu entusiasmo na sala de aula; também está relacionado com suas habilidades de apresentação, que envolve seus conhecimentos de didática. Segundo a autora, o professor dinâmico é confiante, articulado e animado.

Outra característica do bom professor, apontada pelos alunos foi a alegria e extroversão. "A extroversão é a atitude na qual a pessoa se sente mais à vontade com o mundo dos objetos e das outras pessoas, estando mais interessado em seu impacto sobre o mundo. Tende a ser mais sociável e mais consciente quanto ao que está acontecendo a sua volta. Precisa prevenir-se de ser dominado pelos eventos externos e alienado de seu mundo interior" (PEREIRA \& FALEIRO, 2010 p. 29). Por exemplo, um professor severo que não tem compreensão de sentimentos ou relacionamentos é um clássico estereótipo de extroversão desequilibrada. A tipologia de Jung é especialmente útil para nos auxiliar a compreender os relacionamentos que ocorrem na sala de aula, pois descreve como as pessoas percebem de modos alternos e utilizam diferentes critérios ao agir e fazer julgamentos, Pereira \& Faleiro (2010).

Outros aspectos também foram valorizados pelos alunos, entre eles estão: receptivo a mudanças $(6,7 \%)$, escolher a profissão por vocação $(5,5 \%)$, autoridade $(4,8 \%)$. O aluno não deseja negar a autoridade de seus professores. O que ele rejeita é o autoritarismo que permeia 
essa relação, "engessando" o aluno, tirando-lhe o direito de expressão, fazendo com que este tenha um comportamento "dócil", "manso", acatando, dessa forma, todas as práticas pedagógicas, mesmo que desmotivantes, entediantes, sem contestá-las. O professor deve definir as expectativas e traçar os limites dos seus alunos, e o mais importante é conseguir que eles sejam aceitos, sendo essa a principal fonte de tensão pedagógica (TELLES et. al., 2015). O aluno simplesmente "cumpre as regras do jogo", sem se preocupar em adquirir o conhecimento, e desejando o término do curso o mais rápido possível, obtendo, assim, ascensão social. Dessa forma, ele não consegue vislumbrar o impacto que isso terá em seu desempenho na futura vida profissional, Sordi (1995).

Porém, para de fato acompanhar todas as transformações, os educadores terão que modificar suas antigas práticas e se abrir para novas maneiras de atuação. E terão que se especializar para terem o domínio sobre os novos instrumentos. É fundamental que cada professor ache seu jeito de ensinar, de utilizar os novos meios em sala, de se comunicar com os alunos. E é importante também que estas aulas sejam diversificadas, criativas. O professor terá que repensar o seu papel, abandonar o poder do saber absolutizado e buscar discutir novas práticas pedagógicas compatíveis com as exigências do mundo moderno. Pode-se notar que a prática pedagógica dos educadores diante de tantas influências, rupturas e transformações que adentraram nas salas de aula, na escola, na conduta dos professores, nos alunos, na metodologia e na avaliação até os dias de hoje, permaneceu extremamente enraizadas em padrões de repetição do ensino e na explanação dos conteúdos. E claro, neste contexto, a tecnologia pena para conseguir ter espaço nos processos de ensino-aprendizagem (WEBER \& BEHRENS, 2010).

E por fim, os professores do ensino superior, não raro, são advindos de outras profissões, como por exemplo, médicos, engenheiros, advogados e assim por diante. A sua identificação profissional como professor geralmente fica em segundo plano. O termo "professor universitário" só é usado quando vem acompanhado do adjetivo "universitário". É evidente, então, que o título de professor, isoladamente, sugere uma identidade menor, transmitindo um conceito social primário e secundário (PIMENTA; ANASTASIOU, 2010, p. 35). Para esses autores essa questão revela toda a problemática profissional do ensino superior, tanto na questão do que significa ser professor quanto nas condições concretas do exercício profissional da docência. Portanto, a questão da escolha de ser "professor" pode ser identificada, nestes fragmentos, na medida em que a vocação surge como uma das principais justificativas pela própria escolha.

Tabela 3 : Características relacionadas ao bom professor segundo os universitários

\begin{tabular}{lcc}
\hline \multicolumn{1}{c}{ Características } & Respostas & $\mathbf{F \%}$ \\
\hline Amizade & 128 & 11,8 \\
Saber se expressar & 122 & 11,2 \\
Atualizado & 120 & 11,0 \\
Domínio do conteúdo & 107 & 9,8 \\
Criativo & 100 & 9,2 \\
Dinamismo & 90 & 8,3 \\
Alegre e extrovertido & 89 & 8,2
\end{tabular}

Persp. online: hum. \& sociais aplicada., Campos dos Goytacazes, 22 (8), 37-51, 2018 seer.perspectivasonline.com.br 


\begin{tabular}{|c|c|c|}
\hline Metodologia diversificada & 88 & 8,0 \\
\hline Receptivo a mudanças & 72 & 6,7 \\
\hline Escolher a profissão por vocação & 60 & 5,5 \\
\hline Autoridade & 52 & 4,8 \\
\hline Paciência & 36 & 3,3 \\
\hline Experiência & 24 & 2,2 \\
\hline
\end{tabular}

Fonte: elaborada pela autora

Nota-se que as características que obtiveram a menor porcentagem foram experiência $(2,2 \%)$, seguida de paciência (3,3\%). O aluno não deseja o professor "bonzinho", mas aquele "intelectualmente capaz e afetivamente maduro". A competência não é necessariamente proporcional aos anos de prática, nem o melhoramento do ensino se processa de forma automática. Quintana (2003) ressalta que o professor deve exercer uma função de mediador, facilitando o processo de aquisição e apropriação do conhecimento. Essa mediação deve acontecer na utilização de pautas interativas, que favoreçam as trocas, as discussões, a reflexão crítica, a cooperação mútua e o intercâmbio entre pares, a ação interativa que se denomina "didática pedagógica". Em relação a característica paciência Luft (2000) diz que é uma virtude que consiste em suportar os males ou incômodos com resignação e tolerância. Para Cristino et. al., (2008) a paciência é um dos saberes necessários à prática docente.

\section{CONCLUSÕES}

O estudo da percepção das características de um bom professor tem sido um tema muito debatido em Psicologia da Educação, em área afim. Dessa forma, o propósito principal da pesquisadora, no presente estudo, foi identificar as características mais importantes, na opinião de estudantes universitários, de um bom professor.

Os resultados encontrados neste estudo revelaram que seis cursos (Psicologia, Letras, Enfermagem, Biologia, Química e História) os quais fizeram parte da pesquisa, apontaram características referentes à dimensão didático-pedagógica como sendo a mais importante para o professor exercer a profissão. E os cursos de Pedagogia e Geografia apontaram como características importantes àquelas relacionadas às categorias relação professor/aluno e pessoais/personalidade. Portanto, o bom professor, para os nossos graduandos, é aquele que conhece profundamente a disciplina que leciona, tem clareza e linguagem fácil em suas explicações, admite e demonstra haver maneiras diferentes de ensinar, demonstra segurança e domínio de si na condução do ensino, não faz discriminações entre alunos, não é irônico, indelicado e não humilha o aluno, sabendo organizar o ensino e, por fim, não grita, ameaça, ou seja, não é grosseiro com seus aprendizes.

O panorama da relação professor/aluno mudou completamente. Veiga (2004) preconiza que um dos fatores que influenciaram essa mudança foi justamente o fato de a universidade ter ganhado, nos últimos anos, um público mais amplo. A autora ainda afirma que a relação, hoje, não é só pedagógica, mas, também, social, profissional e afetiva. Essa relação pedagógica não é mais um campo para a homogeneização. Atualmente há muitas diferenças sociais, e, em razão disso, os alunos são heterogêneos e, muitas vezes, esses professores não estão preparados para analisar esses novos valores da forma como deveriam. 
Os resultados também revelaram que o aluno busca por um profissional mais próximo, interessado e preocupado com eles, os estudantes. Características de um profissional amigo, respeitável, encorajador e que permita que o discente também participe da interação ensino e aprendizagem, para a criação de um ambiente favorável a essa relação em sala de aula.

Uma nova linha de pesquisa em Psicologia Educacional vem demonstrando que, ao contrário do que se pensava anteriormente, não são as características de personalidade do professor, e sim suas ações em sala de aula, influenciam diretamente na aprendizagem dos alunos. Essas ações, por sua vez, estão fundamentadas numa determinada concepção do papel do professor, que reflete valores e padrões de uma determinada sociedade. Portanto, aspectos sociais, culturais e até políticos condicionam as formas do relacionamento professor-aluno, produzindo tipos diferentes de ação em sala de aula, tornando o papel do professor cada vez mais complexo e ambíguo, Santos (2001).

A possibilidade de o professor ser capaz de implementar interações significativas entre o aluno e o objeto de conhecimento, ou seja, interações que efetivamente promovam o desenvolvimento e a aprendizagem, são objetos de estudo de Del Prette (1994), e este autor acrescenta ainda que tais interações incluem a participação mais direta do professor, além das atividades nas quais a participação é mais indireta, de suporte e de mediação.

Quando um facilitador cria, mesmo em grau modesto, um clima de sala de aula caracterizado por tudo que pode empreender de autenticidade, apreço e empatia, quando confia na tendência construtora do individuo e do grupo; descobre então, que inaugurou uma revolução educacional. Ocorre uma aprendizagem de qualidade diferente, um processo de ritmo diverso, com maior grau de penetração. Sentimentos positivos, negativos e difusos tornam-se uma parte da experiência de sala de aula; a aprendizagem transforma-se em vida, vida existencial. Dessa forma, o aluno, às vezes com entusiasmo, relutantemente em outros casos, comporta-se como alguém que está passando por uma aprendizagem, por certa mudança.

Portanto, "no contexto educacional atual, o desenvolvimento da docência reveste-se de novos desafios no que se refere ao conhecimento pedagógico, científico e cultural exigido aos professores, com aumento de responsabilidades atribuídas à necessidade de lidar com uma maior diversidade de estudantes, com distintas capacidades de aprendizagens, requerendo capacidade de organizar e sistematizar informação, mobilizar conhecimentos e motivar os estudantes para propiciar as aprendizagens". (VENTURA et al., 2011, p. 96)

Entretanto, é preciso reconhecer que é muito importante a interação professor-aluno para a educação em qualquer nível, seja na formação pré-escolar até a formação universitária, já é um grande passo em direção às mudanças necessárias. Contudo, em face da investigação realizada e disponível nesta área, muitos esforços devem ainda ser realizados para compreensão e a delimitação empírica e conceitual das características fundamentais da relação professor-aluno. Os dados obtidos indicaram a necessidade de futuras investigações com as séries mais avançadas, a fim de avaliarem se essas características realmente pertencem ao perfil do bom professor. Sugere-se que estas características possam ser estudadas em hierarquia de preferências, para apresentação de futuros resultados.

Por sua vez, "as IES precisam estar consciente da importância do professor no processo ensino e aprendizagem, propiciando a ele condições de trabalho, como subsidiar cursos de capacitação didático-pedagógica, para que ele possa ensinar o aluno a pensar e formar cidadãos que questionem a realidade e busquem soluções originais e criativas, além de proporcionar a abertura para novas possibilidades de estratégias ativas de ensino e aprendizagem" (LAZZARIN, NAKAMA \& CORDONI JR., 2007 p. 99). 


\section{REFERÊNCIAS}

ALONSO, K. M. Algumas considerações sobre a educação a distância, aprendizagens e a gestão de sistemas não presenciais de ensino. In: PRETI, O. (Org.). Educação à distância: ressignificando práticas. Brasília: Liberlivro Editora, 2005. p. 17-38.

BARDIN, L. Análise de conteúdo. Lisboa: Edição 70, 1984.

CANDAU, V. M. A didática e a formação de educadores: a busca da relevância. Textos, n. 06, p. 37-41, 1983.

CUNHA, M. I. O bom professor e sua prática. 20a . ed. Campinas: Papirus, 2008.

CUNHA, A. C. Representação do "bom" professor: o "bom" professor em geral e o "bom" professor de educação física em particular. Educação em Revista, 11 (2), p. 41-52, 2010.

CRISTINO, A. P. da R. et al. Os saberes necessários à prática docente em Educação Física Escolar. In: congresso de educação física e ciências do desporto dos países de língua portuguesa, 12, 2008, Porto Alegre. Anais, Porto Alegre: ESEF/UFRGS, 2008.

DE SORDI, M. R. A prática de avaliação do ensino superior: uma experiência na enfermagem. São Paulo: Cortez/Campinas: PUCAMP; 1995.

DEL PRETTE, Al., DEL PRETTE. Z. Interações sociais em sala de aula: representações do professor. In: Anais do XVII International School Psychology Colloquium e II Congresso Nacional de Psicologia Escolar. p. 426-430, 1994.

DEMO, P. Formação permanente e tecnologias educacionais. Petrópolis: Vozes, 2006.

Metodologia para quem quer aprender. São Paulo: Atlas, 2008.

DUDERSTADT, J. J. A university for the 21st century. Ann Arbor: University of Michigan Press, 2003.

FEITOZA, L. A; CORNELSEN, J. M; VALENTE, S. M. P. Representação do bom professor na perspectiva dos alunos de arquivologia. Perspectivas em Ciência da Informação. Vol. $12, \mathrm{n}^{\circ} 2$, p. 158-167, 2007.

FREIRE, P. Pedagogia do oprimido. Rio de Janeiro: Paz e Terra. 2005.

GABRIELLI, J. M. W; PELÁ, N. T. R. O professor real e o ideal na visão de um grupo de graduandos de enfermagem. Revista Escola de Enfermagem USP. 38 (2), 168-174, 2004.

GISI, M. L; ENS, R. T; EYNG, A. M. Politicas educacionais e a representação de estudantes de pedagogia sobre o que é um bom professor. Educação, Sociedade \& Culturas, n 31, p. 51-66, 2010.

KNIGHT, A. B. Teacher Credibility - A tool for diagnosing problems in teacher/student relationships. Publicado no site da Universidade de Oklahoma http://www.ou.edu. 2002.

Persp. online: hum. \& sociais aplicada., Campos dos Goytacazes, 22 (8), 37-51, 2018

seer.perspectivasonline.com.br 
KOCHHANN, A. Por uma pedagogia psicanalítica: as vicissitudes na formação de professores. Dissertação de mestrado em Educação com área de concentração em Psicanálise. Goiânia: 2007. 228 p.

KRUG, R. de R; KRUG, H. N. As características pessoais do bom professor na opinião dos acadêmicos da licenciatura em Educação Física do CEFD/UFSM. WWW.efdeportes.com. Revista Digital, Buenos Aires. Ano 13 (126), 2008.

LAZZARIN, H. C; NAKAMA, L. \& CORDONI Jr., L. O papel do professor na perspectiva dos alunos de odontologia. Saúde e Sociedade, 6 (1), p. 90-101, 2007.

LUFT, C. P. Minidicionário Luft. São Paulo: Ática/Scipione, 2000.

MARQUES, V. A. et al. Atributos de um bom professor: um estudo sobre a percepção dos alunos de ciências contábeis. Revista de Contabilidade e Controladoria, 4 (2), p. 7-23, maio/agost. 2012.

MARTINS, C. B. A formação de um sistema de ensino superior de massa, In: SAMPAIO, H. (Org) O ensino superior no Brasil: o setor privado. São Paulo: Fapesp/Hucitec, 2000.408 páginas.

MENEGAZ, J. do C. et al. O bom professor na área da saúde: uma revisão integrativa. Revista de Enfermagem, 8 (4) p. 1048-1056, 2014.

MAHONEY, A. A. Contribuições de H. Wallon para a reflexão sobre as questões educacionais. In: Placco, V. S. (Org.), Psicologia \& Educação: Revendo contribuições pp 9$32,2002$.

MORIN, E. Os saberes necessários à educação do futuro. 11. Ed. São Paulo: Cortez, 2006.

PASQUALI, L. Psicometria: teoria dos testes na psicologia e na educação. Petrópolis: Vozes, 2013.

PEREIRA, A. L. P; FALEIRO, S. N. Competência interpessoal do professor em sala de aula, desejo ou necessidade? Revista destaques acadêmicos, ano 2, n. 3, 2010.

PIMENTA, S. G; ANAStASIOU, L. das G. C. Docência no ensino superior. 4.ed. São Paulo: Cortez, 2010.

QUINTANA, M. S. Ação psicopedagógica na universidade. www.psicopedagogia.com.br/opinião/opinião, 2003. Acessado em 05/07/2005.

SALES, M. P; SOUSA, C. E. B. A manifestação da violência no espaço escolar. Educação Científica (UNIFAP), v. 2, n. 2, p. 55-64, jul-dez, Científica (UNIFAP) 2012.

SANTOS, S. C. O processo de ensino aprendizagem e a relação professor-aluno: aplicação dos sete princípios para a boa prática na educação de ensino superior. Caderno de Pesquisa em Administração, 8 (1) p. 69-82, 2001. 
SILVA, J. P. S. A relação professor/aluno no processo de ensino e aprendizagem. Revista Espaço Acadêmico, $\mathrm{n}^{\mathrm{o}}$ 52, setembro. Disponível em: www.espacoacademico.com.br/052/52pc silva.htm, 2005. Acesso em 6/02/2010.

SILVA, D. M; OLIVEIRA NETO, J. D. O impacto dos estilos de aprendizagem no ensino de contabilidade. In: $7^{\circ}$ Congresso USP de Controladoria e Contabilidade, São Paulo, 26 e 27 de julho de 2007. Anais... São Paulo: 2007

TEIXEIRA, G. Inadequações dos métodos tradicionais no ambiente universitário, www.serprofessoruniversitario.pro.br/, 2004. Acessado em 25/03/2005.

TELLES, C. et al. Os Saberes Necessários ao Bom Professor de Educação Física Escolar na Percepção dos Acadêmicos Ingressantes da Graduação. Revista gestão universitária, 2015. http://www.gestaouniversitaria.com.br/

TEODORO, A. Ensino superior: tendências e desafios no caso português. In: TEODORO, A.; VASCONCELOS, M. L. (Org.). Ensinar e aprender no ensino superior. 2. Ed. São Paulo: Editora Mackenzie, 2005. p. 13-33.

VASCONCELOS, A. A. et al. A presença do diálogo na relação professor-aluno. In: V Colóquio Internacional Paulo Freire, Recife, 19-22 set. 2005. Anais... Recife, 2005.

VEIGA, I. P. A. Orientador não é o detentor único do conhecimento: o que mudou na relação professor/aluno. www.universia.com.br/materia, 2004. Acessado em 01/04/2005.

VENTURA, M. C. A. et al. O bom professor - opinião de estudantes. Revista de Enfermagem Referência, Série III, n 5, p. 95-102, 2011.

WEBER, M. A. L; BEHRENS, M. A. Paradigmas educacionais e o ensino com a utilização de mídias. Revista Intersaberes, Curitiba, a. 5, n.10, p.245-270, jul./dez. 2010 